\title{
CENTRO HISTÓRICO E INVESTIGACIÓN URBANA EN AMÉRICA LATINA
}

\author{
María Luisa Lourés Seoane*
}

Una mirada retrospectiva sobre la investigación urbana en América Latina en los últimos cincuenta años, nos revela su estrecha relación con las corrientes internacionales del pensamiento urbano. Esta vinculación tuvo un doble significado contrapuesto. Si por un lado, la inclusión en un marco de reflexión amplio aportó elementos para el análisis sumamente enriquecedores, por el otro, la asunción acrítica de teorías producidas en contextos políticos, económicos y sociales alejados de Latinoamérica, se tradujo en una trasposición mecánica, tanto de las teorías como de las temáticas de estudio abordadas.

En líneas muy generales, y salvando las diferencias existentes entre los países del continente, se puede considerar que fue a finales de los cincuenta cuando los estudios urbanos en Latinoamérica tomaron carta de naturaleza. Los países de urbanización temprana presentan un cuerpo disciplinar más elaborado que aquellos de urbanización más tardía, cuya incorporación a los estudios urbanos se fue produciendo hasta fechas no muy lejanas. Así, tensando el arco temporal hasta sus extremos, México y Argentina estarían incluídos entre los primeros, mientras los países centroamericanos y del Caribe se encontrarían entre los últimos. Siguiendo a L. Valladares y M. Prates (1996), si en los primeros años, la dicotomía entre lo urbano y lo rural concentró gran parte de la investigación urbana, en la década siguiente los fenómenos demográficos y las cuestiones relativas a la marginalidad urbana como consecuencia de la hiperurbanización creciente, constituyeron temas prioritarios de investigación, convirtiéndose el funcionalismo en clave interpretativa de estos fenómenos.

Ya en los años setenta, bajo la influencia del pensamiento marxista y en especial de la sociología urbana francesa, se produjo una relectura del fenómeno urbano que iba a romper con el paradigma positivista de la etapa anterior. Economistas, sociólogos, geógrafos, arquitectos, etc, participaron en el análisis de lo urbano con un pensamiento crítico renovado ${ }^{1}$. El papel del Estado en la conformación de la ciudad, el rol protagónico de los llamados movimientos sociales urbanos, los equipamientos colectivos, etc, ocuparon un papel central en la investigación. Los contactos entre Europa, especialmente Francia, y América Latina se estrecharon, dando lugar a multitud de estudios en ambos lados del océano en uno de los períodos intelectuales más vigorosos que se hayan conocido (Ch. Topalov, 1990).

L. Kowarick (1992) señala cómo los análisis urbanos realizados en América Latina bajo la vertiente estructuralista del marxismo, exceptuando el trabajo de E. Pradilla, fueron asimiladas sin que mediase crítica alguna.

Ya en los años ochenta y noventa, las ciudades afrontaron una serie de cambios estructurales tan determinantes que tanto las interpretaciones como los instrumentos utilizados anteriormente, se mostraron insuficientes para el análisis. Con la crisis del paradigma marxista, los estudios urbanos empezaron a dirigirse en múltiples direcciones, a la descripción detallada de las particularidades, alejadas de cualquier contexto-marco que pudiese otorgarles sentido. A propósito de estas nuevas tendencias en los estudios urbanos franceses, B. Ganne (1987) se interroga sobre el carácter de las nuevas temáticas de investigación:

"En efecto, bajo la apariencia de la apertura, uno no puede dejar de interrogarse sobre el marco restringido en el cual los nuevos temas asignados a la investigación urbana se encuentran cuidadosamente encerrados, limitados al sólo nivel local y al sólo aspecto "cualitativo" de los modos de vida" (B. Ganne, 1987:149).

En América Latina, tras una década donde los estudios urbanos se vieron fuertemente comprometidos en su continuidad por la crisis económica y política y la falta de recursos destinados a la investigación, a finales de los ochenta se multiplicaron los estudios de tipo micro, utilizándose escalas territoriales mínimas. Proliferaron los estudios barriales, de modos de vida y en general de todo aquello que guardase relación con lo inmediatamente próximo.

Fue precisamente en estos años, y no por casualidad, cuando el estudio de los centros históricos irrumpió con fuerza en la agenda de las investigaciones urbanas en

1. Para profundizar en el estudio de las relaciones entre las Ciencias Sociales y el Urbanismo consultar: F. Choay (1982), F. Terán (1985), F. Díaz Orueta (1995). 
América Latina ${ }^{2}$. La celebración de Congresos y Seminarios internacionales, así como los programas de cooperación internacionales, se mostraron como vehículos transmisores de la producción científica del momento.

\section{INVESTIGACIÓN/POLÍTICA URBANA (1980/90)}

En el marco de una profunda reestructuración económica, signada fuertemente por la aplicación de las políticas de ajuste estructural y por la reorganización del aparato estatal orientada a la aplicación del nuevo modelo de acumulación, las preocupaciones, tanto de los gobiernos nacionales como de los organismos financieros internacionales $^{3}$, se fueron decantando hacia los efectos sociales que provocaron la aplicación de dichas políticas. El hundimiento en la pobreza de grandes masas de población, acabó expresándose muy nítidamente en las ciudades, donde la visibilidad del fenómeno es hoy insoslayable. Una vez admitida la irreversibilidad del cambio económico emprendido, sus acciones se dirigieron a mitigar los efectos. Al respecto, el "Programa Urbano del Banco Mundial para el decenio de 1990", se muestra muy elocuente cuando, en su punto 2 , se propone como objetivo "el alivio de la pobreza urbana". El carácter del alivio resulta fácilmente deducible, si tenemos en cuenta que el propio Banco Mundial sostiene la necesidad del:

“(...) reconocimiento y el apoyo de los esfuerzos de los pobres por satisfacer sus propias necesidades a través de iniciativas comunitarias y organizaciones locales no gubernamentales" (Banco Mundial, 1995: 66) ${ }^{4}$.

Las exigencias de los organismos financieros fueron eficazmente interpretadas por los gobiernos nacionales quienes, rápidamente, se ofrecieron a traducir el nuevo modelo a un discurso ciudadano digerible por aquéllos que iban a ser los principales perjudicados. La construcción de ese discurso contó con el grupo más o menos amplio de intelectuales, capaces de otorgar legitimidad a un proceso que, claramente, profundizaba en las desigualdades sociales. Para esta tarea, no faltaron apoyos internacionales de colegas bien alejados de las realidades latinoamericanas. El discurso político se alimentó de las bases "científicas" aportadas por los estudios de caso, a la vez que la ciudad se acomodaba al "nuevo orden mundial". Sin duda, no faltaron voces críticas capaces de suministrar una contralectura de los fenómenos urbanos que se estaban produciendo, pero fueron las menos.

Más allá de experiencias concretas en algunas áreas y en ciertos países que no respondieron a los esquemas generales, durante estos años la agenda urbana para el continente se sustentó sobre ciertos principios generales compartidos:

a) Como producto de la reorganización del aparato estatal, se replanteó la relación entre el sector público y el privado en la organización de la ciudad. El desprestigio de lo público, como sinónimo de ineficaz y corrupto fue alentado, fundamentalmente, desde el propio aparato estatal. La transferencia de competencias al sector privado que, hasta el momento habían sido propias del Estado, fueron ensanchándose llegando a abarcar esferas altamente sensibles, como el suministro de servicios básicos.

b) El planeamiento clásico fue rechazado como instrumento de intervención urbana. Este fue considerado un instrumento dogmático, rígido e incapaz de organizar de modo coherente la ciudad. En contraposición, el proyecto urbano se configuró cómo el instrumento más adecuado de intervención por su flexibilidad, inmediatez y capacidad de intervención puntual y concreta.

c) El ámbito local se perfiló como el nivel óptimo para el gobierno de la ciudad. Las virtualidades del mismo venían dadas, básicamente, por constituir una esfera próxima al ciudadano. Por lo tanto, con mayores capacidades democráticas y desde el cual se podían ofrecer mejores servicios.

d) Unido a lo anterior, la descentralización y la participación ciudadana. El ciudadano pasó a ocupar el centro de la escena, otorgándosele toda clase de capacidades de intervención en lo público, a la vez que se achicaba dicha esfera.

Si bien todos estos elementos sobre los que giraba tanto la reflexión en materia urbana, como su plasmación en los discursos y agendas de política urbana, estaban presentes en el escenario internacional, no puede decirse que su significado fuese idéntico en todos los países. Por poner sólo un ejemplo, el sentido de la descentralización política, administrativa y económica no es el mismo en el Reino Unido, España, Argentina o Brasil.

2. J. E. Hardoy y M. Gutman (1992), destacan el incremento notable registrado durante los últimos años de las reuniones internacionales en torno a esta cuestión.

3. Existe una evidente vinculación entre los recursos destinados a la investigación urbana por parte de los organismos financieros internacionales y de otras organizaciones internacionales, y las temáticas de estudio y prioridades seleccionadas. En este sentido, L. Valladares y M. Prates (1994) señalan como de la información suministrada en este sentido para Argentina, Chile, Ecuador y Uruguay se deduce: “(...) que la investigación urbana depende esencialmente de la financiación extranjera procedente de dos fuentes principales: a) los organismos internacionales (PNUD, BID, UNCHS), cuyos recursos se obtienen por conducto de un organismo estatal encargado de distribuir los fondos asignados al país; y b) los organismos internacionales públicos y privados dedicados a la realización de investigaciones y al fomento del desarrollo (SAREC, IDRC, FORD, VOLKSWAGEN, NOVIB), cuyos recursos se encauzan hacia los centros de investigación privados y las ONGs" (L. Valladares y M. Prates, 1996:18).

4. El documento del Banco Mundial se refiere permanentemente a "los pobres" cómo una categoría dada, donde quedarían incluidos aquellos individuos cuya incapacidad les impide salir de esa situación. Se pertenece al grupo de los "pobres" como se pertenece a una casta, no parecería haber ningún tipo de razones externas, de responsabilidades políticas o sociales. Por ejemplo, el surgimiento de los nuevos sectores sociales empobrecidos, provenientes en gran parte de la clase media, se debería a su falta de habilidad para hacer frente a la nueva situación creada por las políticas de ajuste. 


\section{Los centros históricos}

En este contexto, gran parte de la filosofía discursiva en torno a los centros históricos en América Latina se nutrió de fuentes contrapuestas. Por un lado, gran parte de la retórica investigadora se inspiró en el discurso centrohistoricista europeo de finales de los años sesenta y los setenta, cuyo mayor grado de elaboración teórico-práctica se localizó en la Emilia-Romagna italiana ${ }^{5}$. Sin embargo, al traducir los presupuestos de la política reformista que inspiraron ese discurso al plano de las realidades concretas de los países latinoamericanos, tanto los análisis como las propuestas se convertieron en altamente incongruentes, transmutándose discursos, prácticas, tiempos históricos y realidades sociales diferentes en un cúmulo ininteligible.

Por otro lado, y como señala F. Carrión:

“(...) el desarrollo teórico y conceptual sobre el campo de los centros históricos es muy escaso, hasta el grado que campea la empiria y el voluntarismo. Más que un proceso de conceptualización que permita definir el quehacer teórico-práctico, lo que existe son un conjunto de recomendaciones surgidas de reuniones que operan como referentes teóricos para la comprensión e intervención en los centros históricos; con lo cual se suplantan los marcos teóricos y se los acoge acrítica y esquemáticamente como si fuesen normas" (F. Carrión, 1992: 62).

En este sentido, cabe señalar el papel que los Congresos Internacionales sobre los centros históricos y el patrimonio urbano en general, tienen en la conformación de criterios rectores del pensamiento y de una especie de acuerdo tácito que parece existir en lo relativo a la recuperación del centro histórico. Y es, precisamente, esa ausencia de debate la que hace sospechar que el pensamiento sobre el centro histórico no está incardinado con la realidad política, económica y social en la que se encuentra inmerso. Gran parte de las investigaciones realizadas, muestran, junto a una descripción más o menos pormenorizada de las características físico-espaciales del área concreta de estudio y, en menor medida, de las demográficas y sociales, una serie de aseveraciones referidas a la necesidad de incluir la intervención sobre el centro histórico dentro del Planeamiento general para la ciudad, garantizar el derecho de los sectores populares a residir en estos lugares, el papel protagónico que el municipio debe adquirir en todo este proceso, la necesidad de participación de los residentes en el área, etc. Sin embargo, todo esto no es más que una música de fondo que no logra encontrar su lugar real en la investigación, al no explicar ésta el significado de ese espacio en la ciudad. De esta forma, la secuencia suele ser la siguiente: descripción del proceso de urbanización de la ciudad que se trata, acotamiento del área histórica, descripción de la riqueza espacial del lugar, descripción del deterioro físico y vagas menciones a un deterioro social y recomendaciones que señalan la pertinencia de una recuperación no sólo física sino social. En medio, continuamos sin conocer el significado último de ese espacio en la ciudad y el papel que juega, en la actualidad, en el proceso de reacomodación de las clases sociales en el espacio. En suma, se trata de acercamientos epidérmicos que, lógicamente, acaban por explicar muy poco y señalar lo obvio.

\section{LA EXPERIENCIA EMILIANA DE LOS SETENTA}

Conviene detenerse brevemente en las características que comportó la experiencia emiliana, aunque sólo sea por la gran influencia ejercida posteriormente en el pensamiento sobre los centros históricos y poder reconocer en el discurso latinoamericano aquellos elementos que se retomaron de la misma.

En efecto, la crisis internacional del capitalismo, que ya se venía fraguando desde tiempos atrás y que se manifestó claramente desde los años setenta, situó en un primer plano de los análisis urbanos los "principios de la austeridad" formulados por G. Campos Venuti (1981), y publicados en Italia por primera vez en 1978. Según el propio autor:

"La esencia de la austeridad urbanística se podría resumir: dirigirse más al interior que al exterior del organismo urbano, buscar una reorganización de la ciudad existente antes que su expansión indiscriminada, cuidar la calidad de la vida ciudadana en vez de aumentar el número de habitantes" (G. Campos Venuti, 1981: 57).

Por otra parte, se planteó también lo que se llamaría el "Plan de las cinco salvaguardias", destinadas a la protección integral de la ciudad y el territorio. Estas fueron:

1.- Pública: contra la privatización de los espacios.

2.- Social: contra la expulsión de los habitantes del centro histórico.

3.- Productiva: contra la expulsión de las industrias de las ciudades.

4.- Ambiental: contra el deterioro de la naturaleza y del centro histórico.

5.- Programática: contra la desprogramación del sistema de viabilidad.

Durante estos años, la izquierda gobernante en la mayoría de los municipios mostró la voluntad política de dirigir la administración de la ciudad. En conjunción con las fuerzas sociales y organizaciones sindicales, trató de llevar adelante planes de intervención en la ciudad, con los que se intentaba atajar los efectos nefastos producidos por la renta urbana. De este modo, se planteó inundar la ciudad de servicios sociales y espacios verdes. A la vez, se trató de establecer una relación más fluída entre los barrios periféricos y el centro. El centro histórico pasó a ser defendido de los ataques a los que había estado sometido y los sectores económicamente más débiles manifestaron su deseo de permanencia en él, haciendo valer su "derecho a la ciudad”. Así, el proyecto de recuperación del centro histórico

5. Toda la experiencia europea posterior, en mayor o menor medida se considera deudora de la italiana. En España, durante los años ochenta, se concretaron un número importante de intervenciones en los centros históricos que, en alguna medida, partieron de aquellos objetivos de la política reformista italiana. 
quedó ligado a la vivienda social en el mismo. La defensa del centro histórico se incluyó dentro de un programa más amplio para toda la ciudad donde se contemplaban, tanto aspectos legislativos, físico-espaciales, ambientales, de provisión de servicios y transporte, etc. Todo ello, con la participación activa de la población en el proceso de construcción de la ciudad. Evidentemente, el contexto en que se desenvolvían los estudios urbanos en aquellos años, con múltiples aportaciones desde las ciencias sociales, así como la efervescencia social y política del momento confluyeron en un punto en el que el proyecto político se vinculó de forma clara con un proyecto social para la ciudad ${ }^{6}$.

Ya en la década siguiente, bajo las teorías posmodernistas, el proyecto social subyacente en la defensa/recuperación del centro histórico quedaría sepultado, y la rehabilitación de la mano de la Arquitectura adquiriría el carácter prestigiante y de "culto" característico de etapas anteriores. La "recualificación urbana" fue el objetivo de esta etapa. La recuperación urbana ya no se pretendía "integral", sino esencialmente física.

Durante estos años el área definida como histórica se fue ampliando permanentemente, desbordando con creces los límites que señalaban el centro histórico. El conjunto urbano se consideró como un todo histórico digno de ser respetado. Esto, sin embargo, no llegó a tener su correlato en la práctica urbana.

\section{TRASLADO AL CONTINENTE AMERICANO}

En el discurso latinoamericano sobre el centro histórico, básicamente sostenido por profesionales pertenecientes al ámbito académico y técnicos de las áreas de planeamiento urbano, se mezclaron elementos de análisis e intervención relativos al período de la "recualificación urbana", con otros pertenecientes al período anterior. Dos modos de entender este espacio radicalmente diferentes. El problema no residiría tanto en la adecuación o no a un modelo preestablecido, cómo en la ausencia de una reflexión profunda acerca del modelo de ciudad sobre la que se está actuando y/o analizando y el proyecto de ciudad que se reclama, un proyecto que, necesariamente, debe ser político. En definitiva, el desconocimiento de la propia realidad social permite situar en el corazón del análisis la cuestión patrimonial sólo porque en Europa, ahora, es lo último que domina el debate?

El contexto económico, político, cultural que alumbró el proyecto reformista italiano no es comparable con la situación actual italiana ni, obviamente, con la realidad latinoamericana.

El proyecto centrohistoricista se desplegó en una red de ciudades medias, en el marco de una gran movilización popular en su lucha por la vivienda y gobiernos municipales sólidos, que se habían propuesto combatir los efectos negativos de la renta urbana en su búsqueda de una ciudad más equitativa. Pese a la crisis económica, en este área sus efectos no fueron tan acusados como en las áreas industriales tradicionales, precisamente por la existencia de una red de ciudades repartidas de un modo equilibrado en el territorio con un desarrollo también equilibrado. Fue, lo que se denominó "Terza Italia".

Si bien el proyecto social subyacente es plenamente válido para ambos lados del Atlántico, no cabe más referirse a situaciones que no son reales: el contexto de crisis económica permanente, la movilización popular fragmentada en miles de demandas urgentes de la vida cotidiana, la debilidad de los gobiernos municipales, la ausencia de un proyecto político para la ciudad, la ausencia de inversiones en viviendas e infraestructuras, la privatización de los espacios, etc, obligan a pensar el centro histórico en términos diferentes a los exclusivamente patrimoniales. Reivindicar únicamente la piedra, puede ser tanto o más perjudicial para estas áreas como las intervenciones urbanas, pasadas o presentes, dirigidas a su desaparición física. Junto con ello, es preciso acometer la tarea de la elaboración de un pensamiento propio que deje de ser deudor de teorías producidas pensando en otras realidades sociales y físico-espaciales. Todos estos planteamientos deberían sumarse a otros que, desde diferentes ramas de los estudios urbanos, vienen llamando la atención en los últimos años sobre la necesidad de redefinir conceptos, reconsiderar ciertos esquemas explicativos y, en definitiva, de adecuar la investigación y la práctica a la nueva realidad urbana.

\section{BIBLIOGRAFÍA}

Banco Mundial. (1995), Política urbana y desarrollo económico: un programa para el decenio de 1990, Washington: Banco Mundial.

Campos Venuti, G. (1981), Urbanismo y austeridad, Madrid: Siglo XXI.

CARRIÓN, F. (1992), "Quito: una política urbana alternativa”, Medio Ambiente y Urbanización, 38.

CHOAY, F. (1982), "Arquitectura y Urbanismo", en: DuFRENE, M. y otros, Corrientes de investigación en las Ciencias Sociales, Madrid: Tecnos: UNESCO.

DíAZ ORUETA, F. (1995), "La sociología urbana en la encrucijada” en: Díaz Orueta, F. y Mira, E., Pensar y Vivir la ciudad, Alicante: Departamento de Ciencias Sociales.

6. No se desconoce el carácter especulativo que también tuvo la rehabilitación de los centros históricos. En este sentido, es posible referirse a los procesos de "gentrification", cuyo término fue acuñado en 1964 por Ruth Glass en su estudio sobre Londres.

7. En este sentido, en los últimos años en Buenos Aires, "la ciudad de lujo" encontró en la rehabilitación patrimonial una veta para expresar se. Prescindiendo de su propia realidad social inmediata, no consideró necesario ningún compromiso con la misma. Mientras el área histórica, asiento de una población claramente heterogénea donde todos los grupos sociales se encuentran representados, se va cayendo día a día, un frenesí rehabilitador se desplegó por la ciudad: las Galerías Pacífico, se destinaron a shopping; los antiguos galpones colorados de Puerto Madero a usos diversos (oficinas, equipamientos educativos privados, etc); los antiguos Silos de Dorrego, para oficinas y viviendas de alto standing; el antiguo edificio de la Chrysler, para viviendas de lujo; los "lofts" del barrio sur del arquitecto O. Giesso; los "lofts" de Darwin en antiguos establecimientos industriales; etc. Por fin, los defensores en exclusiva de la "memoria histórica" pueden descansar tranquilos: poco a poco, los edificios contemporáneos van a sucedernos en el tiempo. Mientras tanto, la vida puede esperar (M.L. Lourés, 1996). 
GANNE, B. (1987), "Las vicisitudes de las investigaciones urbanas", Sociológica, 4.

GLass, R. (1964), London: Aspects of change, London: Centre for Urban Studies and MacGibbon and Kee.

GuTIÉRREZ, R. (1992), Arquitectura y Urbanismo en Iberoamérica, Madrid: Cátedra.

Hardoy, J. E. y Gutman, M. (1992), Impacto de la urbanización en los centros bistóricos de Iberoamérica, Madrid: MAPFRE.

KOWARICK, L. (1992), "Investigación Urbana y Sociedad: comentarios sobre nuestra América”, Sociológica, 18.

LOURES, M. L. (1996), Buenos Aires: centro bistórico y crisis social, Madrid: Universidad Complutense (tesis doctoral).
TERÁN, F. (1985), "Sobre la crisis actual de los fundamentos teóricos del planeamiento" en: CAMPOS Venuti, G. y otros, Teoría e intervención en la ciudad, Madrid: Fundación de Investigaciones Marxistas.

Topalov, Chr. (1990), "Hacer la historia de la investigación urbana. La experiencia francesa desde 1965", Sociológica, 12.

Valladares, L. y Prates, M. (1996), La investigación urbana en América Latina. Tendencias actuales y recomendaciones, MOST-UNESCO, Documentos de Debatae, n. ${ }^{\circ} 4$.

\section{RESUMEN}

El estudio del centro histórico cobra un gran impulso en los años 80 y 90 . Deudor del pensamiento europeo en la materia, no ha conseguido crear un corpus teórico original que le vincule con su propia realidad política, económica y social. Repensar su significado en el contexto urbano que le otorga sentido, a la vez que desprenderse de una visión exclusivamente físico-patrimonial, constituyen tareas necesarias.

\section{ABSTRACT}

Historic centre studies have received a major boost during eighties and nineties. Indebted to european thought, it hasn't been able to create an original theory, linked by their own political, economical and social reality. Rethinking its meaning into urban context and to shake off an exclusively patrimonial point of view, are necessary tasks. 